\title{
Ocular disorders in children with learning disabilities in a tertiary Hospital, Pondicherry
}

\author{
Ganapathy Kalaiselvi ${ }^{1}$, Dinu Kumar, ${ }^{2, *}$ \\ ${ }^{\mathbf{1}}$ Assistant Professor, ${ }^{\mathbf{2}}$ Associate Professor, Dept. of Ophthalmology, Aarupadai Veedu Medical College and Hospital, \\ Kirumampakkam, Pondicherry, India
}

*Corresponding Author:

Email: dinuarthur@gmail.com

\begin{abstract}
Aim: To assess the visual function of the children with disabilities and to identify the preventable and treatable ocular abnormalities.

Materials and Methods: This was a cross sectional hospital based study which included the children aged between 3 to 16 years with learning disabilities (cLDs, previously referred to as mentally challenged) who were on speech and occupational therapy sessions. After consent from parents or guardian who accompanied the child, relevant medical history was taken. Detailed ocular examination, visual acuity assessment, cycloplegic retinoscopy of all children was done. Spectacles and low vision aids were prescribed appropriately.

Results: A total of 116 children with learning disabilities were enrolled. There were $79(68.1 \%)$ males as compared to 37 $(31.9 \%)$ females in the study. Eighty eight children (76\%) had ocular disorder, 31 children had more than one ocular abnormality and 51 of them were not cooperative for assessment. The most common ocular disorders seen in these children were 48 (54.5\%) children had refractive errors, strabismus in 17 (19.3\%) children, followed by nystagmus in 15 (17\%) children, Only 7 of the 48 children $(14.6 \%)$ with refractive error were using spectacles.

Conclusion: The prevalence of ocular abnormalities is higher among the children with disabilities than in general population. Their flawed verbal, poor communication and cooperation add on to the burden of their disabilities as the ocular abnormalities go unnoticed. Therefore there is a need for strategies regarding increasing awareness, annual comprehensive ophthalmic assessments, early detection and treatment of the ocular disorders to assist these children in their learning process.
\end{abstract}

Keywords: Children with learning disabilities, Refractive error, Strabismus, Special needs.

\section{Introduction}

Vision plays an important role in the development of a child. Uncorrected vision affects the child's performance at various levels. In children with disabilities, vision is one of the important senses on which they depend on, for their understanding and communication with the outer world. ${ }^{1}$ In India among 26.8 million people suffering from one or the other type of disability 7.8million are children aged 0-19 years accounting for $29 \%$ of the total disabled population as per census conducted in $2011 .^{2}$

In children with learning disabilities (cLDs, previously referred to as mentally challenged or retarded) visual problems are relatively common but as the priorities are on the primary disability, the visual impairment and its assessment are often overlooked. ${ }^{3,4}$ On the other hand the ocular examination in these children with learning disabilities is a challenge and needs patience, skills and a broader range of assessment instruments. $^{1}$

Studies have reported higher incidence of ophthalmological abnormalities in children with learning disabilities. ${ }^{1,3-6}$ The presence of more than one disability in an individual can have multiplicative rather than an additive effect on their life experience. ${ }^{7}$ Thus, even a minor visual problem, reducing their visual clues, needs to be identified and addressed at the earliest in order to optimize their social and academic performance.
The aim of the present study was to identify the visual disorders among children with learning disabilities who had been attending speech and occupational therapy clinics.

\section{Materials and Methods}

The study was approved by Institutional Ethical Committee. All children (children < 16 years, as defined by $\mathrm{WHO}$ ) with learning disabilities who were attending speech and occupational therapy clinics in our institution between September 2015 and August 2016 were enrolled in our study. The examination process was explained to the parent or guardian accompanying the children. Those children whose parents did not give consent for the examination were excluded from the study. Written informed consent was taken from the parent or guardian who accompanied the child. Relevant details regarding the disability, family history, birth history, history of consanguinity was recorded. Intelligence quotient (IQ) had been assessed earlier using the Binet-Kamat method ${ }^{8}$ at the Psychiatry department and recorded.

Ocular examination was carried out in diffuse illumination with a flash light to observe head posture and facial anomalies. Snellen's E-chart was used for assessing visual acuity in children who could read and co-operate. For other children, visual acuity was tested using picture charts or Cardiff's preferential looking tests. Near vision testing was done at $33 \mathrm{~cm}$ followed by 
distant vision testing at 6 meters. Hirschberg's light reflex test and cover uncover test was used to evaluate visual axis and strabismus. Ocular movements were tested and presence of nystagmus was checked. Anterior segment was examined using torch light and slit-lamp examination. Direct and consensual pupillary light reflexes were also checked.

Subjective correction of refractive errors was attempted in children who were cooperative. Cycloplegic retinoscopy was done in all children using $0.3 \%$ cyclopentolate eye drops after ascertaining that the child didn't have seizures. In case of history of seizures, $0.5 \%$ homide eye drops were used. A detailed fundus examination after dilatation was done by direct ophthalmoscope. Myopia was defined as spherical equivalent of more than or equal to -0.5 diopter (D), hypermetropia as more than or equal to $+1.0 \mathrm{D}$ and astigmatism as more than or equal to $\pm 0.5 \mathrm{D}$. Spectacle prescription was given to all children with refractive errors.

The data was entered using an excel sheet and analyzed using SPSS software version 22. The data was expressed using descriptive statistics.

\section{Results}

The study included a total of 116 children, with learning disabilities who were attending speech and occupational therapy clinics. Out of the 116 children,
$39(33.6 \%)$ were in the age group of 3 to 9 years and 77 $(66.4 \%)$ were in the age group of 10 to 16 years. There were $79(68.1 \%)$ males as compared to $37(31.9 \%)$ females in the study. A stormy perinatal history was seen in $56(48.3 \%)$ children, $22(18.9 \%)$ had positive family history of learning disability/cognitive impairment and $28(24.1 \%)$ had positive history of consanguinity.

Out of 116 children examined $88(76 \%)$ had ocular disorders and 31 children had more than one ocular abnormality. For visual acuity assessment 51 children were not cooperative, 22 children cooperated for Snellen's E-chart, 26 children by picture chart, 17 children by Cardiff preferential looking charts.

The most common ocular manifestation observed in the study was refractive errors, present in $54.5 \%$ children. Strabismus was the second most common finding, seen in $19.3 \%$ children followed by nystagmus in $17 \%$ children. Corneal opacity and optic atrophy were seen in 3 children each. Retinitis pigmentosa, microphthalmia (uniocular), corneal dystrophy were noted in two children each, while 2 children were found with congenital cataract. Coloboma of iris, lens, choroid and retina was seen in one child. One of the child presented with retinal detachment as an ROP sequelae. Fig. 1 shows the ocular problems found in children with learning disability.

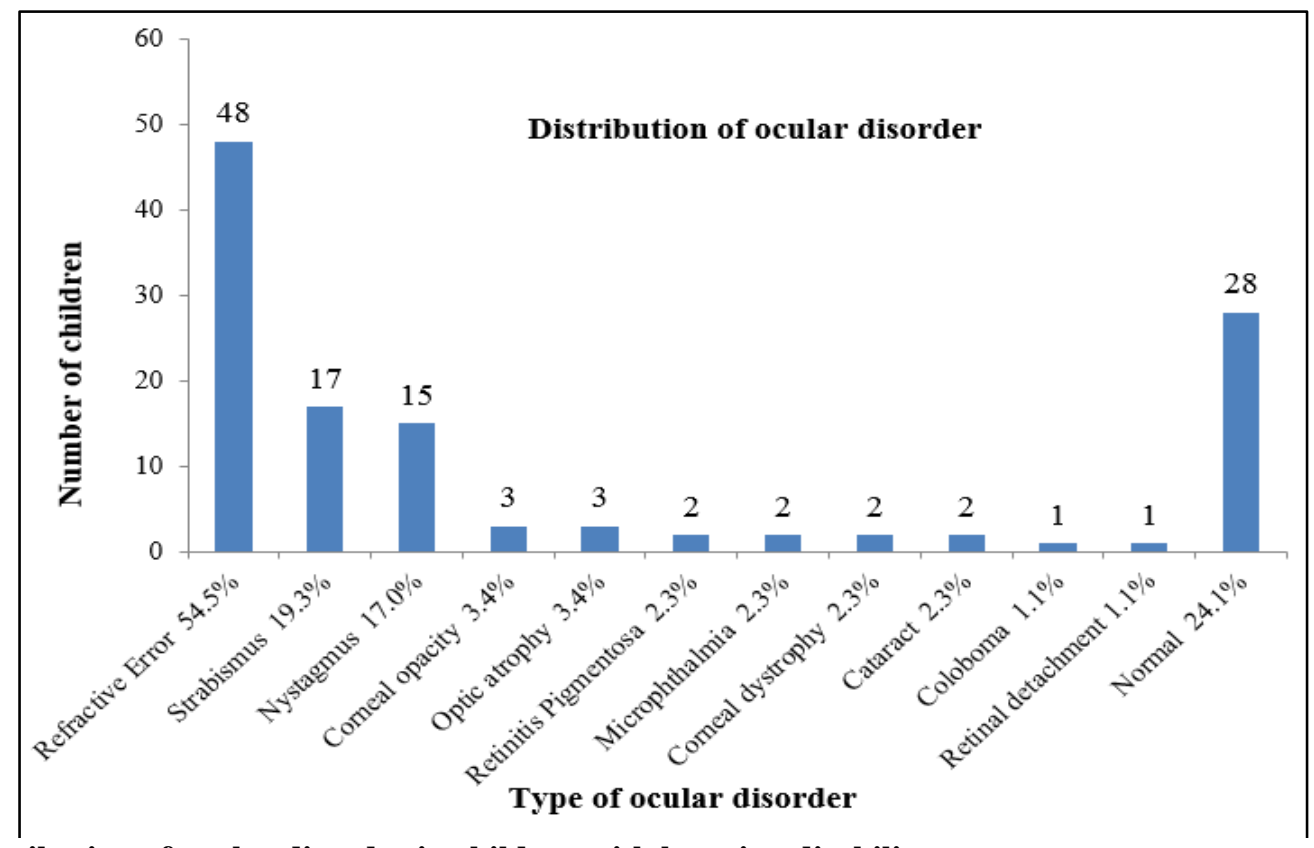

Fig. 1: Distribution of ocular disorder in children with learning disability

Refractive error was seen in 48 children $(54.5 \%$ of ocular problem). Of them, refractive error was present in both eyes in 39 children $(81.2 \%)$ whereas 10 children $(20.8 \%)$ had in one eye only. The most common type of refractive error was simple myopia in 36 eyes $(40.91 \%)$, followed by astigmatism in 32 eyes
(36.36\%), hypermetropia in 12 eyes (13.64\%) and high myopia in 8 eyes $(9.09 \%)$ as shown in figure 2 . Among the astigmatism, simple myopic astigmatism was the commonest type of astigmatism noted in 14 eyes $(43.75 \%)$ followed by compound myopic astigmatism in 8 eyes $(25.0 \%)$, simple hypermetropic astigmatism in 
6 eyes (18.75\%), compound hypermetropic astigmatism in 4 eyes $(12.5 \%)$. Only 7 of the 48 children $(14.6 \%)$ had been previously corrected for their refractive error. Spectacles were prescribed to all 31 children who had been found to have refractive error and new corrected prescription of glasses was given to the rest 7 children who were using glasses.

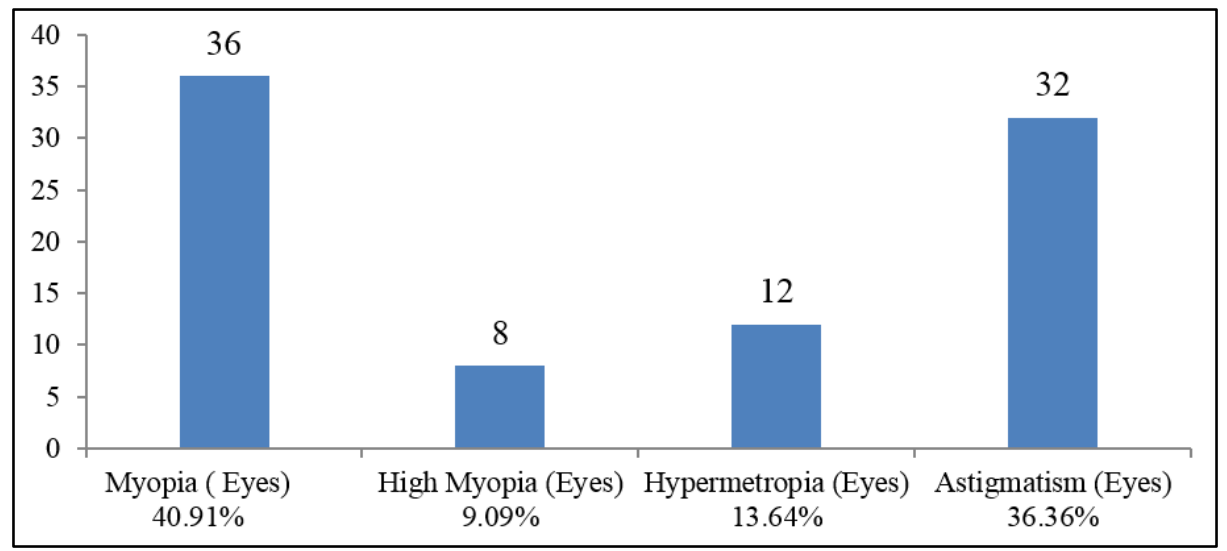

Fig. 2: Distribution of refractive error in children with learning disability

Of the $17(19.3 \%)$ children who had strabismus, 10(58.8\%) had exotropia and 7(41.2\%) had esotropia, 3 of whom had surgery. Two children with cataract underwent cataract surgery and the child with retinal detachment underwent surgery. Children with retinitispigmentosa and retino choroidal coloboma were offered low-vision aids.
The distribution of IQ scores along with number of children with ocular problems is presented in Table 1 .

Of the five profoundly mentally retarded children, two of them had optic atrophy, one with microphthalmia and another child had corneal opacity. The number of students having ocular problem among severe and profound mentally disability, $80.77 \%$ and $80.0 \%$ respectively was more as compared to $73.33 \%$ in mild and $75.0 \%$ in moderate mental disability.

Table 1: Distribution of ocular disorders in association with severity of mental retardation

\begin{tabular}{|l|c|c|}
\hline \multicolumn{1}{|c|}{ Mental Disability (I.Q.) } & $\begin{array}{c}\text { Total No. of } \\
\text { Students }\end{array}$ & $\begin{array}{c}\text { No. of Students with Ocular } \\
\text { Morbidity No. (\%) }\end{array}$ \\
\hline Mild (50 - 69) & 45 & $33(73.33 \%)$ \\
\hline Moderate (35- 49) & 40 & $30(75.0 \%)$ \\
\hline Severe $(22-34)$ & 26 & $21(80.77 \%)$ \\
\hline Profound $(<20)$ & 5 & $4(80.0 \%)$ \\
\hline Total & 116 & 88 \\
\hline
\end{tabular}

\section{Discussion}

Children with learning disabilities face many challenges including poor communication skills and intellectual disabilities affecting their overall development. If visual problems get added to their already existing disability, it has a negative impact on the quality of their life as they are entirely dependent on the visual inputs for their understanding and communication with outer world. Thus visual problems need to be identified and addressed at the earliest.

Our study found that $76 \%$ of the children with learning disabilities had ocular problem. Gogate et al in special schools of Pune reported 45.3\%, ${ }^{1}$ Gurvinder Kaur et al in special schools of North India reported $43 \%{ }^{9}$ and Joshi RS et al in Nagpur reported $51.45 \%$ of children with disabilities having ocular problems. ${ }^{10}$

Refractive error $(54.5 \%)$ followed by strabismus $(19.3 \%)$ were the most common ocular problems noted in our study. A similar observation was noted in Gogate et al with refractive error $27.3 \%$ followed by strabismus $15.8 \% .^{1}$ Bankes found $49 \%$ mentally handicapped children had some form of refractive error. ${ }^{11}$ In a series of 134 intellectually challenged students in Nepal, refractive errors were found in $67.9 \% .^{12}$ Vora $\mathrm{U}$ et al had reported $58.5 \%$ of refractive error among the special children in Oman. ${ }^{13}$

Among the refractive errors of the children with learning disabilities, myopia 50\% (simple myopia $40.91 \%$ and high myopia $9.09 \%$ ) the commonest type, followed by astigmatism $36.3 \%$ and hypermetropia $13.6 \%$ were noted in our study. Gurvinder Kaur et al had reported myopia commonest in $13.1 \%$ children with disabilities followed by hypermetropia in $6.7 \%$ and astigmatism in $3.2 \% .^{9}$ Warburg found the prevalence of myopia to be at $43 \%$ and of hypermetropia at $21 \%$ in severe/profoundly 
intellectually impaired adults. ${ }^{14}$ Vora $\mathrm{U}$ et al had reported astigmatism in $27.1 \%$ followed by myopia in $24.3 \%$ and hypermetropia in $18.6 \%$ of special kids. ${ }^{13}$ Ghising R et al had reported hypermetropia 50.3\% followed by myopia $24.9 \%$ and astigmatism at $24.8 \% .^{12}$

In our study $19.3 \%$ of children with learning disabilities had strabismus. Similar observation was noted by Gogate et al in $15.8 \%,{ }^{1}$ Gurvinder Kaur et al in $18.1 \%{ }^{9}$ and Vora $\mathrm{U}$ et $\mathrm{al}^{13}$ in $14.3 \%$ of children with special needs. Strabismus could be due to amblyopia, binocularity is usually lost. Binocular vision disruption at early age affects the development of the child and hinders the learning process. Therefore strabismus should be corrected at an early age and appropriate orthoptic management should be attempted.

Nystagmus was found in $17 \%$ of children in our study, Gurvinder Kaur et $\mathrm{al}^{9}$ reported in $16.6 \%$ while Gogate et $\mathrm{al}^{1}$ and Vora $\mathrm{U}$ et $\mathrm{al}^{13}$ reported in $6.8 \%$ and $4.3 \%$ respectively. Children with nystagmus have reduced vision and difficulties in fixation leading to a huge hurdle in their developmental process. In our study both the children with congenital cataract had nystagmus as well.

Early identification of these potential and additional barriers to their learning and development may result in a better quality of life in these children with special needs. In these intellectually challenged children, the other disabilities are prioritized and the need for eye care often remains unnoticed or neglected. Refractive error correction at early age prevents amblyopia and prevents the child from compromised living with avoidable blindness. The fact that majority of the causes of visual impairment like refractive errors, strabismus, leading to amblyopia are easily treatable, signifies the need for regular ocular assessment in these children with disabilities. ${ }^{1,7,13}$

There were only $14.6 \%$ children who were evaluated earlier and were using spectacles in our study, while Gogate et $\mathrm{al}^{7}$ reported as low as $6 \%$ and Vora $\mathrm{U}$ et $\mathrm{al}^{13}$ reported $13.6 \%$. Woodhouse et al recently reported that half of a cohort of children attending special schools had refractive errors warranting new or first-time spectacle prescription. ${ }^{15}$ Studies of children with special needs have established that there are significant unmet visual needs in a high proportion of children, who were undiagnosed. ${ }^{3}$

The ocular problems were noted to be more as the severity of mental disability increases in our study as in Joshi RS et al who reported a significant association between the severity of mental disability and ocular morbidities. ${ }^{10}$ The assessment may be more challenging as the severity of mental disability increases. Das et $\mathrm{al}^{16}$ stated that 'the manner in which an eye test is conducted is most important' and emphasized the importance of carrying out tests in a familiar environment. Ocular disorders may not be recognized without careful assessment and are frequently unidentified in children with complex needs. ${ }^{6}$ To meet the visual needs of children with disability, stronger links are needed between child development and community paediatric services, ophthalmology and specialist education services for children with special needs.

However awareness among parents and care takers are still lacking. Many parents believed that someone needs to be communicable verbally for to undergo eye examination, some of them feared that their child might injure themselves using spectacles and some felt that their child did not need spectacles.

\section{Conclusion}

Periodic screening of these children with learning disabilities and proper counseling of their parents and care takers about the importance of screening and the correction of the visual problems, provide a greater chance of improvement in their milestones and well being. There need to be a clear guidelines and closer working between all professionals involved in the care of the children with disabilities to provide a new horizon in their lifetime.

\section{References}

1. Gogate P, Soneji FR, Kharat J, Dulera H, Deshpande M, Gilbert C. Ocular disorders in children with learning disabilities in special education schools of Pune, India. Indian J Ophthalmol. 2011;59(3):223-28.

2. Punarbhava- National Interactive Portal on DisabilityCensus of India 2011 Data on Disability. [Online]. Cited 2014 January 08; Available from URL: http://www. Punarbhava.in

3. Welinder LG, Baggesen KL. Visual abilities of students with severe developmental delay in special needs education - a vision screening project in Northern Jutland, Denmark. Acta Ophthalmol. 2012;90(8):721726.

4. Woodhouse JM, Davies N, McAvinchey A, et al. Ocular and visual status among children in special schools in Wales: the burden of unrecognised visual impairment. Arch Dis Child. 2014;99(6):500-504.

5. Nielsen LS, Skov L, Jensen H. Visual dysfunctions and ocular disorders in children with developmental delay. I prevalence, diagnoses and aetiology of visual impairment. Acta Ophthalmol Scand. 2007;85(2):149-156.

6. Alison Salt, Jenefer Sargent Common visual problems in children with disability. Arch Dis Child. 2014;99(12):1163-1168.

7. Gogate P, Rishikeshi N, Mehta R, Deshpande M, Ranade $\mathrm{S}$. Vision impairment in the hearing impaired. Ind $J$ Ophthalmol. 2009;57(6):451-3.

8. Kamat V. Measuring intelligence of Indian children. Oxford: Oxford university press; 1967.

9. Gurvinder Kaur, Satish Thomas, Mahesh Jindal, SM Bhatti. Visual Function and Ocular Status in Children with Disabilities in Special Schools of Northern India. $J$ Clin Diagn Res. 2016;10: NC01-NC04

10. Joshi RS, Somani AA. Ocular disorder in children with mental retardation. Indian J Psychiatry. 2013;55(2):170172.

11. Kennerley Bankes JL. The ophthalmologist's role in multidisciplinary assessment of developmentally handicapped children. Br J Ophthalmol. 2006;90:1297303. 
12. Ghising R, Shakya S, Rizyal A, Shrestha R, Shrestha S, Wang-Harris S. Prevalence of refractive error in mentally retarded students of Kathmandu Valley. Nepal Med Coll J. 2007;9(4):262-265.

13. Vora U, Khandekar R, Natrajan S, Hadrami KA. Refractive error and visual functions in children with special needs compared with the first grade school students in Oman. Middle East Afr J Ophthalmol. 2010;17(4):297-302.

14. Warburg M. Visual impairment in adult people with moderate, severe, and profound intellectual disability. Acta Ophthalmol Scand. 2001;79(5):450-454.

15. Woodhouse JM, Davies N, McAvinchey A, et al. Ocular and visual status among children in special schools in Wales: the burden of unrecognised visual impairment. Arch Dis Child. 2014;99(6):500-504.
16. Das M, Spowart K, Crossley S, et al. Evidence that children with special needs all require visual assessment. Arch Dis Child. 2010;95(11):888-92.

How to cite this article: Kalaiselvi $G$, Kumar D. Ocular disorders in children with learning disabilities in a tertiary Hospital, Pondicherry. Ind J Clin Exp Ophthalmol. 2018;4(3):347-351. 